\title{
An epidemiological survey of eight oil refineries in Britain
}

\author{
L RUSHTON AND M R ALDERSON
}

From the Division of Epidemiology, Institute of Cancer Research, Sutton, Surrey SM2 SPX, UK

ABSTRACT A mortality study of workers employed for at least one year between 1 January 1950 and 31 December 1975 at eight oil refineries in Britain has been carried out. Over $99 \%$ of the population were successfully traced to determine their vital status at 31 December 1975. The mortality observed in the study population was compared with that which would be expected from the mortality rates for the all male population of England and Wales, and Scotland, with adjustment for regional variation in mortality for the English and Welsh refineries. The overall mortality observed was considerably lower than that expected on this basis, as was the mortality from heart disease, stroke, bronchitis, and pneumonia. The observed number of deaths from all neoplasms was also very much less than expected, a result almost entirely due to a large deficit of observed deaths from lung cancer. Raised mortality patterns were found in several refineries for cancers of the oesophagus, stomach, intestines, and rectum, although no location was consistently high for all these causes of death. Different yearof-entry cohorts and job groups were also affected. In general, mortality from these causes increased as length of service and interval from starting work increased. There were also significantly more observed deaths than expected from cancer of the nasal cavities and sinus, and melanoma. Further work is required to ascertain whether these are due to an occupational factor and, if so, to identify the physical or chemical nature of the risk.

The aim of this study was to examine the patterns of mortality by cause for employees in oil refineries in Britain. In addition to providing background information on the health of the workers this could draw attention to specific problem areas that might require further investigation. A full report of the study has been completed. ${ }^{1}$ The purpose of this article is to describe the method of data collection and analysis, to give the full results in detail, and to discuss some of the problems encountered in the approach selected and in the interpretation of results from this type of study.

\section{Previous studies on the hazards associated with oil}

The carcinogenic properties of mineral oil have been well documented. Both experimental ${ }^{2} 3$ and occupational studies have been reported in the shale oil industry and in the textile industry. ${ }^{4-7}$ Particular issues in the petroleum industry that have

Requests for reprints to $L R$.

Received 11 June 1980

Accepted 9 September 1980 been investigated include exposure to benzene in petrol, ${ }^{8} 9$ risks to workers in asphalt, ${ }^{10}$ and the occurrence of cancer, especially skin cancer and cancer of the scrotum, in wax pressmen. ${ }^{11-13}$

In a mortality study of 17 selected refineries in the United States 20000 workers were grouped into three broad categories of exposure to polycyclic hydrocarbons by using their job titles. ${ }^{14}$ Overall mortality was appreciably less than that of the all male United States population. Mortality from cardiovascular-renal diseases, digestive cancers, and ulcers of the stomach and duodenum was highest in men with the lowest exposure to hydrocarbons. Mortality from respiratory cancer, lymphomas, and genital cancer increased with increasing exposure to hydrocarbons, although only for lymphomas was mortality greater than expected in all exposure groups.

In a smaller study of workers in an oil refinery in Canada the overall mortality was again much lower than expected. ${ }^{15}$ A non-significant excess was found for cancers of the digestive system.

Three studies of the petroleum industry have also reported raised mortality from cancers of the 
digestive system. ${ }^{16-18}$ Refinery workers in Canada had twice the risk of cancer of the intestines (including rectum) and cancer of other digestive organs compared with non-refinery workers. ${ }^{16}$ Employees exposed to crude petroleum or its products were found to have three times the risk of cancers of the oesophagus and stomach and twice the risk of lung cancer compared with non-exposed employees.

Proportional mortality ratios (PMR) for cancers of the liver, pancreas, lung, and skin were raised among refinery and petrochemical workers in Texas, although the risks did not increase with duration of membership. ${ }^{17}$ Increased relative frequencies of stomach cancer, cancer of the brain, leukaemia, and multiple myeloma were found in white men in the same industrial category with a membership of ten or more years. An analysis of deaths from three particular refineries showed increased risks from brain, stomach, and lung cancer, each of these risks occurring at two of the three refineries.

Thirty-nine petroleum industry counties in the United States, where at least 100 people were employed and at least $1 \%$ of the county population were estimated to be petroleum company employees, were compared with 117 counties matched for geographic region, population size, and various demographic indicators. ${ }^{18}$ Significant excesses from cancer of the stomach and of the rectum were found for men in the more highly populated petroleum industry counties compared with male residents in other counties. Significantly higher rates were also found in the petroleum industry counties for cancers of the lung, nasal cavities and sinus, skin, and testis.

\section{Method}

The present study included all men who had worked for at least one continuous year between 1 January 1950 and 31 December 1975 at eight refineries in Britain. In this article the refineries are denoted by A, B, C, D, F, G, H, and J. A feasibility study had suggested that the survey should include only men with a minimum of ten years' service, and the refineries were selected partly because they employed sufficient men who satisfied this criterion. The minimum length of service, however, was reduced to one year to increase the numbers in the study, and to allow a comparison between men with longer and men with shorter periods of service.

The study excluded women as comparatively few are employed in the refineries. Men who could be identified as having spent a great part of their career abroad were also excluded. The mortality of this group would be difficult to relate to that of the other refinery workers as they may have worked in very varied environments. The date 1 January 1950 was chosen as a starting date for the study because, although some of the refineries had been "on stream" much earlier than this, their personnel records were thought to be complete only after this date.

The following data were collected for each man in the study from refinery personnel systems: full name, date of birth, address, date of joining, last or present job, and whether a day or shift worker. For leavers, date of leaving, reason for leaving (retired, died, or other), National Insurance number or National Health Service number, or both, were also collected.

In the feasibility study consideration had been given to collecting a detailed job history for each man, including dates for changing jobs. Retrieval of these data would have been costly and also a lengthy clerical task. There was also some doubt as to how complete and accurate the information was and how job history could be related to exposure to various potential hazards, many of which would be undocumented. It was therefore decided to use a broad classification of occupation-for instance, the various crafts, operators, laboratory and scientific, clerical, and administrative-based on the last job title. In interpreting the results the limitations of last job title as an indication of job history must be recognised-for example, a man may take a less strenuous job than his main job for the last few years of employment due to ill health.

Information on pensioners, including date of death, was available from some companies. All other leavers, where contact with the company had been lost, were traced either through the social security records at Newcastle using the National Insurance number or through the National Health Service Central Registers (NHSCR) at Southport and Edinburgh using the NHS number or through both systems if necessary. This procedure took about 18 months to complete. Full details of death were obtained from the NHSCRs, the Office of Population Censuses and Surveys (OPCS), and the Registrar General for Scotland.

At all stages of data preparation checks were carried out on the accuracy and plausibility of the data and to eliminate duplicate records. When a duplicate record was found, the man concerned was counted as a leaver (or present employee) from the last refinery mentioned, although his total duration of service at all refineries was included as relevant to the study. Duplication of records and movement between refineries was found for those refineries belonging to the same company and for those of different companies, particularly between refineries $A$ and $\mathrm{H}$. Over $\mathbf{4 0 0}$ duplicate records were found. 
The underlying cause of death and up to three contributory causes were coded using the appropriate revision of the International Classification of Diseases (ICD). ${ }^{19}$ In the analysis the underlying cause was used in comparing observed with expected deaths. The contributory causes were used to identify other cases where the disease of interest was an associated cause rather than the underlying cause of death.

The number of years each man was in the study (person-years), subdivided into five-year age and calendar period groups, was calculated from his date of birth, and dates of entry to and exit from the study using the Man Years Computer Language program. ${ }^{20}$ As all men in the study had a minimum of one year's service between 1 January 1950 and 31 December 1975 the date of entry to the study was 1 January 1951 for men who joined the refinery before 1950, and one year after joining for those who joined after 1 January 1950. Expected deaths were obtained by applying five-year age and calendar period death rates of the comparison population to the person-years.

The comparison population used was the population of men in England and Wales for the English and Welsh refineries and in Scotland for the Scottish refineries.

The available comparison data determined the grouping of the causes of death. For 30 malignant causes the groups were those used in the serial mortality tables. ${ }^{21}$ For the non-malignant causes, data for the A list of 150 causes of death from the 7 th Revision of the ICD were made available by the World Health Organisation.

CORRECTION FOR REGIONAL AND SOCIAL CLASS VARIATION IN MORTALITY

The basis for calculating an estimate of the expected number of deaths is a compromise between the matching of factors likely to influence the risk of death (other than issues being specifically explored, such as occupation) and the availability of suitable death rates. Various approaches use: national mortality rates; subsets of the national data, such as rates for regions of a country or for social classes in the population; comparable industry rates; rates for the total population in a specific industry; and internal comparisons within an industry of one category of worker against another. The advantages of the national data are ease of availability and stability due to the large numbers on which they are based. Industry data may be biased because of specific environmental hazards, fluctuate from chance variation in small numbers, and are not readily, today, available.

Mortality rates for different causes vary con- siderably in parts of Britain, and although account has been taken of this to a limited extent by using different comparisons for England and Wales, and Scotland, it was thought that some adjustment for differences in regional mortality should be made for the results for the English and Welsh refineries.

The most readily available published data that covered the major disease groups used were for the Registrar General's (RG) Standard Regions. Those disease groups for which data were not available for the standard regions were relatively minor causes of death, with less than ten observed deaths in this study. Standardised mortality ratios (SMR) for the regions in which the refineries are located were available in the RG's annual Statistical Reviews 1963-75 and in the RG's Decennial Supplements on Area Mortality for 1951, 1961, and 1971. For each disease group, regional SMRs and the number of deaths on which these were based were extracted from the above sources for all available years. A single regional SMR for each disease group and each region was calculated as follows:

(1) The range of the set of SMRs available in each region was calculated for each disease group for the various dates in the study period.

(2) If this range was less than or equal to 15 the (unweighted) mean of the available SMRs was calculated.

(3) If the range of SMRs was greater than 15, the expected deaths for each available year was calculated from the SMR and the number of deaths observed for that year. An overall SMR was then calculated from the sum of the observed deaths and the sum of the expected deaths. This was a weighted mean of the individual SMRs, the weights being the expected deaths.

The expected deaths, calculated using the mortality rates for England and Wales, for each refinery and disease group were then multiplied by the appropriate regional adjustment SMR divided by 100 . Those disease groups for which regional data did not exist were left unadjusted.

In addition to differences in mortality between areas, some diseases show well-defined gradients of mortality across the social classes. The social class distribution of the refinery population differs considerably from that of the male population of England and Wales; a far larger proportion is in social classes IV and $\mathrm{V}$ and a smaller proportion in social classes I and II in the study population (table 1). There are also differences in social class distribution between the regional population and the national population. The adjustment for regional differences in mortality may thus have adjusted partly for social class differences between the refinery population and the national. 
Table 1 Social class distribution of study population compared with that of England and Wales

\begin{tabular}{lcccccc}
\hline & $I+I I^{*}$ & III Non-manual & III Manual & IV & V & Total \\
\hline $\begin{array}{l}\text { Study population } \\
\begin{array}{l}\text { England and Wales 10\% census } \\
\text { population 1971. Men aged 15-64 (not } \\
\text { including unclassified or unoccupied) }\end{array}\end{array}$ & $15 \cdot 0 \%$ & $5 \cdot 3 \%$ & $34 \cdot 6 \%$ & $31.8 \%$ & $13 \cdot 3 \%$ & $100 \%$ \\
\hline
\end{tabular}

*I and II taken together because study job group "scientific and technical" includes chemists (social class I) and laboratory technicians (social class II).

It has been shown, however, that age and social class standardisation had virtually no effect on the SMRs for regions when compared with the SMRs obtained with age standardisation alone ${ }^{22}$-that is, variation in mortality between regions is not explained by differences in social class distribution between the regions. This suggests that regional and social class variation represent more or less separate factors affecting mortality rates.

Fox and Adelstein ${ }^{23}$ suggest that social class standardisation may also be used to investigate the influence of work and environment and lifestyle on mortality by examining how much variation in mortality is accounted for by social class standardisation, the remainder being due to occupation. This assumes that social class is not only a good measure of diet, economic state, educational level, and so on, but is also not confounded with occupation. Social class is by definition related to occupation, so there is some doubt as to whether social class standardisation would completely remove occupational from non-occupational elements.

Age, calendar period, regional, and social class mortality rates are not readily available from published sources. The data for the comparison populations used in this study were immediately available, as were the regional SMRs as described above; SMRs for social class within region are available for only a very restricted list of broad disease groups.

SMRs by social class for England and Wales are obtainable from the occupational mortality decennial supplements. As pointed out, however, in the 1970-2 supplement ${ }^{22}$ the SMRs are artifically high due to the inclusion of the armed Forces and unclassified group in the standard population death rates. The use of these figures would thus result in an overcompensation for social class effects.
Consideration must be given to the classification of refinery process operators $(28 \%$ of the study population) (see table 2), who are classified by the Registrar General as "chemical production process operators not elsewhere classified," and are included in social class IV. Their economic and working conditions, however, do not differ in any appreciable way from those of refinery maintenance men ( $23 \%$ of the study population) who are included in social class IIIM.

In addition to variation in mortality between standard regions, mortality rates vary widely in the smaller areas making up these regions, although many of these figures are based on tiny numbers of deaths. If adjustment figures were available for social class and small areas around the refineries there would be a strong possibility that they would be based, to a large extent, on refinery populations and deaths. This would invalidate their use to correct the study results.

After careful consideration of the above points it was decided that no social class adjustment would be performed. When interpreting the results for the various job groups used in the study, due consideration was given to known social class variation in mortality and an attempt made to judge whether the difference between observed and expected deaths was likely to reflect non-occupational factors.

\section{COMPARISON OF OBSERVED AND EXPECTED DEATHS}

The difference between the observed and expected deaths was examined by calculating a significance level ( $p$ value) for the observed number of deaths assuming it to be drawn from a Poisson distribution with mean equal to the externally calculated expected value.

Two approaches to the analysis were used. The

Table 2 Distribution by job classification of study population $(n=34708)$ (not including untraced men)

\begin{tabular}{|c|c|c|c|}
\hline & No $(\%)$ & & No $(\%)$ \\
\hline $\begin{array}{l}\text { Process operators } \\
\text { Maintenance } \\
\text { Labourers } \\
\text { Storemen } \\
\text { Drivers }\end{array}$ & $\begin{array}{r}9589(28) \\
8092(23) \\
4983(14) \\
481(2) \\
989(3)\end{array}$ & $\begin{array}{l}\text { Fire and safety } \\
\text { Foremen } \\
\text { Scientific and technical } \\
\text { Administrative and clerical } \\
\text { Engineers }\end{array}$ & $\begin{array}{ll}1046 & (3) \\
2489 & (7) \\
2121 & (6) \\
3212 & (9) \\
1706 & (5)\end{array}$ \\
\hline
\end{tabular}


first entailed searching for pronounced excesses and deficits in numbers of observed deaths compared with those expected. A detailed examination of the data by refinery, age, job, year of entry, duration of service, and latent period (the time from start of employment until date of exit from the study) was then carried out to describe and estimate the patterns of mortality more fully. The significance levels were used "informally" as guidelines to indicate the magnitude and direction of the variations in mortality. The second approach consisted of a priori testing of the findings from the previous comparable studies discussed in the introduction.

\section{Results}

Table 3 shows the status of the study population at the study end date 31 December 1975 . Only $0.2 \%$

Table 3 Status of study population at study end date, 31 December 1975

\begin{tabular}{lr}
\hline & $N o(\%)$ \\
\hline In employment & $12525(36 \cdot 0)$ \\
Left employment & $17098(49 \cdot 2)$ \\
Alive & $4403(12 \cdot 7)$ \\
Dead, cause known & $3(0 \cdot 0)$ \\
Dead, cause unknown & $679(1 \cdot 9)$ \\
Emigrated & $73(0 \cdot 2)$ \\
Untraced & $34781(100 \cdot 0)$ \\
Total & \\
\hline
\end{tabular}

of the men were untraced and it is unlikely that the results would have been greatly altered if the vital status of these men had been known. Untraced men were not included in the analysis. There was a total of 575982 person-years of observation in the study with a mean follow-up of $16 \cdot 6$ years for each man.

NON-MALIGNANT CAUSES OF DEATH

The total number of deaths was significantly lower than that expected (table 4), a deficit that is also reflected in most of the disease groups constituting "all diseases of the circulatory system" ( $49 \%$ of the total deaths). The same is true for diseases of the respiratory system, especially tuberculosis, pneumonia, and bronchitis, and also for diabetes, cirrhosis of the liver, and suicide. An excess was found from "accidental fire and explosion," although only 12 such deaths were observed.

In general the pattern of lowered mortality from non-malignant causes of death was found in all subgroups (defined, for example, by job, age, duration of service, etc). Excesses of observed deaths compared with expected deaths were found for labourers for some disease groups (table 5). In
Table 4 Observed and expected cleaths, $O / E$, and $p$ values, for all causes and non-malignant causes with 10 or more observed deaths, for workers employed at all eight refineries in Britain during period 1 January 1950 to 31 December 1975

\begin{tabular}{|c|c|c|c|c|}
\hline Cause (in ICD order) & $\begin{array}{l}\text { Observed } \\
\text { deaths }\end{array}$ & $\begin{array}{l}\text { Expected } \\
\text { deaths }\end{array}$ & $O / E$ & $p$ \\
\hline All causes & 4406 & 5259.95 & 0.84 & $<0.0001$ \\
\hline $\begin{array}{l}\text { Tuberculosis of } \\
\text { respiratory system }\end{array}$ & 25 & $63 \cdot 40$ & 0.39 & $<0.0001$ \\
\hline Diabetes & 15 & $28 \cdot 55$ & 0.53 & 0.0041 \\
\hline $\begin{array}{l}\text { Vascular lesions of central } \\
\text { nervous system }\end{array}$ & 408 & $452 \cdot 02$ & 0.90 & 0.0192 \\
\hline $\begin{array}{l}\text { Chronic rheumatic heart } \\
\text { disease }\end{array}$ & 47 & $74 \cdot 99$ & 0.63 & 0.0004 \\
\hline $\begin{array}{l}\text { Arteriosclerotic and } \\
\text { degenerative heart } \\
\text { disease }\end{array}$ & 1428 & $1589 \cdot 67$ & 0.90 & $<0.0001$ \\
\hline Other diseases of heart & 85 & 113.49 & 0.75 & 0.0038 \\
\hline Hypertensive disease & 76 & $105 \cdot 62$ & 0.72 & 0.0020 \\
\hline Diseases of arteries & 92 & 89.62 & 1.03 & 0.4023 \\
\hline Other circulatory disease & 39 & 37.98 & 1.03 & 0.4557 \\
\hline Influenza & 11 & $27 \cdot 38$ & 0.40 & 0.0003 \\
\hline Pneumonia & 157 & $183 \cdot 24$ & 0.86 & 0.0264 \\
\hline Bronchitis & 253 & $393 \cdot 20$ & 0.64 & $<0.0001$ \\
\hline Asthma & 15 & 18.69 & 0.80 & $0 \cdot 2356$ \\
\hline Peptic ulcer & 50 & $54 \cdot 29$ & 0.92 & 0.3099 \\
\hline Nephritis and nephrosis & 36 & $42 \cdot 30$ & 0.85 & $0 \cdot 1875$ \\
\hline Cirrhosis of liver & 13 & $22 \cdot 09$ & 0.59 & 0.0267 \\
\hline Hyperplasia of prostate & 15 & $17 \cdot 38$ & 0.86 & 0.3395 \\
\hline Motor vehicle accidents & 110 & $101 \cdot 73$ & 1.08 & $0 \cdot 2061$ \\
\hline Accidental poisoning & 13 & $15 \cdot 38$ & 0.85 & $0 \cdot 3278$ \\
\hline Accidental falls & 23 & $30 \cdot 76$ & 0.75 & 0.0910 \\
\hline Accidental fire and & & & & \\
\hline explosion & 12 & 5.98 & $2 \cdot 01$ & 0.0196 \\
\hline Accidental drowning & 15 & $10 \cdot 46$ & $1 \cdot 43$ & $0 \cdot 1096$ \\
\hline Suicide & 62 & $89 \cdot 11$ & $0 \cdot 70$ & 0.0015 \\
\hline
\end{tabular}

Table 5 Observed and expected deaths for labourers for selected causes and refineries

\begin{tabular}{llccl}
\hline Disease & Refinery & $\begin{array}{l}\text { Observed } \\
\text { deaths }\end{array}$ & $\begin{array}{l}\text { Expected } \\
\text { deaths }\end{array}$ & $\begin{array}{l}\text { SMR for social } \\
\text { class } V^{*}\end{array}$ \\
\hline Diabetes & C & 4 & $0 \cdot 97$ & 128 \\
Hypertensive disease & D & 7 & $1 \cdot 67$ & 141 \\
Diseases of arteries & F & 15 & $7 \cdot 27$ & 108 \\
Pneumonia & F & 19 & $12 \cdot 65$ & 195 \\
Pneumonia & J & 27 & $14 \cdot 74$ & 195 \\
Bronchitis & F & 44 & 34.93 & 188 \\
Peptic ulcer & All & 22 & $13 \cdot 19$ & 204 \\
Chronic nephritis & F & 6 & $2 \cdot 09$ & 152 \\
Accidental poisoning & All & 8 & $2 \cdot 82$ & 216 \\
\hline
\end{tabular}

* Men aged 15-64. (Occupational Mortality Decennial Supplement 1970-2.)

addition, excesses were found from diseases of the arteries for fitters at refinery $F(O=6, E=1 \cdot 87$, $\mathrm{p}<0.05)$, from pneumonia for fitters $(0=7$, $\mathrm{E}=2.79, \quad \mathrm{p}<0.05)$ and pipe-fitters $(\mathrm{O}=9$, $E=3.92, p<0.05$ ) at refinery $J$, and from vascular lesions of the central nervous system for operators $(O=35, E=19 \cdot 11, p<0.001)$ at refinery $F$. Three refineries had excesses of deaths from motor vehicle accidents, especially in the younger age groups. At one refinery several apprentices were involved. 
DEATHS FROM MALIGNANT DISEASE

Mortality from all neoplasms (table 6) was significantly lower than expected as was mortality from

Table 6 Observed and expected deaths, $O / E$, and $p$ values, for all neoplasms and malignant causes with five or more observed deaths, for workers employed at all eight refineries in Britain during period 1 January 1950 to 31 December 1975

\begin{tabular}{|c|c|c|c|c|}
\hline Causes (in ICD order) & $\begin{array}{l}\text { Observed } \\
\text { deaths }\end{array}$ & $\begin{array}{l}\text { Expected } \\
\text { deaths }\end{array}$ & $O / E$ & $p$ \\
\hline All neoplasms & 1147 & $1286 \cdot 40$ & 0.89 & 0.0001 \\
\hline Cancer of pharynx & 6 & $7 \cdot 02$ & 0.85 & 0.4467 \\
\hline Cancer of oesophagus & 37 & $32 \cdot 42$ & $1 \cdot 14$ & $0 \cdot 2324$ \\
\hline Cancer of stomach & 167 & $160 \cdot 86$ & $1 \cdot 04$ & $0 \cdot 3143$ \\
\hline Cancer of intestines & 84 & $78 \cdot 87$ & $1 \cdot 07$ & $0 \cdot 2963$ \\
\hline Cancer of rectum & 58 & 56.43 & 1.03 & 0.4348 \\
\hline \multicolumn{5}{|l|}{ Cancer of liver and gall } \\
\hline bladder & 24 & $22 \cdot 84$ & $1 \cdot 05$ & 0.4316 \\
\hline Cancer of pancreas & 50 & $51 \cdot 55$ & 0.97 & 0.4509 \\
\hline Cancer of larynx & 13 & $13 \cdot 37$ & 0.97 & 0.5324 \\
\hline Cancer of lung and pleura & 416 & $532 \cdot 70$ & 0.78 & $<0.0001$ \\
\hline \multicolumn{5}{|l|}{ Cancer of nasal cavities and } \\
\hline sinus & 7 & $3 \cdot 12$ & $2 \cdot 24$ & 0.0399 \\
\hline Melanoma & 14 & $6 \cdot 48$ & $2 \cdot 16$ & 0.0069 \\
\hline Cancer of prostate & 47 & $45 \cdot 87$ & $1 \cdot 02$ & 0.4533 \\
\hline Cancer of urinary bladder & 34 & $44 \cdot 25$ & $0 \cdot 77$ & 0.0669 \\
\hline \multicolumn{5}{|l|}{ Cancer of kidneys and } \\
\hline suprarenals & 22 & $21 \cdot 74$ & $1 \cdot 01$ & 0.5062 \\
\hline \multicolumn{5}{|l|}{ Cancer of brain and central } \\
\hline nervous system & 36 & $44 \cdot 77$ & $0 \cdot 80$ & $0 \cdot 1054$ \\
\hline Reticulum cell sarcoma & 5 & $6 \cdot 76$ & 0.74 & 0.3324 \\
\hline Lymphosarcoma & 11 & $9 \cdot 50$ & $1 \cdot 16$ & $0 \cdot 3547$ \\
\hline Hodgkin's disease & 12 & $16 \cdot 82$ & 0.71 & $0 \cdot 1143$ \\
\hline Multiple myeloma & 11 & $10 \cdot 25$ & $1 \cdot 07$ & 0.4482 \\
\hline Leukaemia & 30 & 31.96 & 0.94 & 0.4089 \\
\hline
\end{tabular}

lung cancer, cancer of the bladder, and cancer of the brain. Slight increases of observed deaths compared with expected were noted for several cancers; this was especially so for neoplasms of the gastro- intestinal tract. Significant excesses were found from cancer of the nasal cavities and sinus, and melanoma, the latter having more than twice as many deaths observed as expected $(\mathrm{O}=14, \mathrm{E}=6.48, \mathrm{p}<0.01)$.

All neoplasms-A pronounced deficit from all neoplasms was found for engineers, scientists, foremen, and administration and clerical workers. Other groups had either the same observed deaths as expected or only a slight deficit, with the exception of labourers, in whom an excess was found $(\mathrm{O}=325$, $\mathrm{E}=294, \mathrm{p}<0.05)$. The overall deficit was very pronounced in those aged under 60 , but the observed deaths for those aged over 60 roughly equalled the expected deaths.

Lung cancer-The four job groups with significant deficits from all neoplasms also showed significant deficits from lung cancer. Mortality from lung cancer for operators was also significantly lower than expected but there were slightly more deaths observed (127) than expected (120) for labourers. For all other job groups, the observed deaths were about the same as expected.

Gastrointestinal cancer-A detailed examination of the data showed an increased mortality from cancer of the oesophagus, stomach, intestines, and rectum, particularly in four refineries $(\mathrm{B}, \mathrm{D}, \mathrm{F}$, and $\mathrm{J})$. Table 7 gives observed and expected deaths, and $\mathrm{p}$ values for excesses found for these disease groups and refineries by job, age, year of entry to the refinery, and duration of service. At refinery $\mathbf{J}$ the mortality from stomach cancer tended to decrease as the duration of service increased. In refinery $F$, however, the opposite pattern was found, with mortality increasing with increasing duration of service (fig 1). Mortality from cancer of the intestines increased with increas-

Table 7 Summary of excesses of observed $(O)$ compared with expected $(E)$ deaths from cancer of the oesophagus, stomach intestines, and rectum by job, age, year of entry, and duration of service

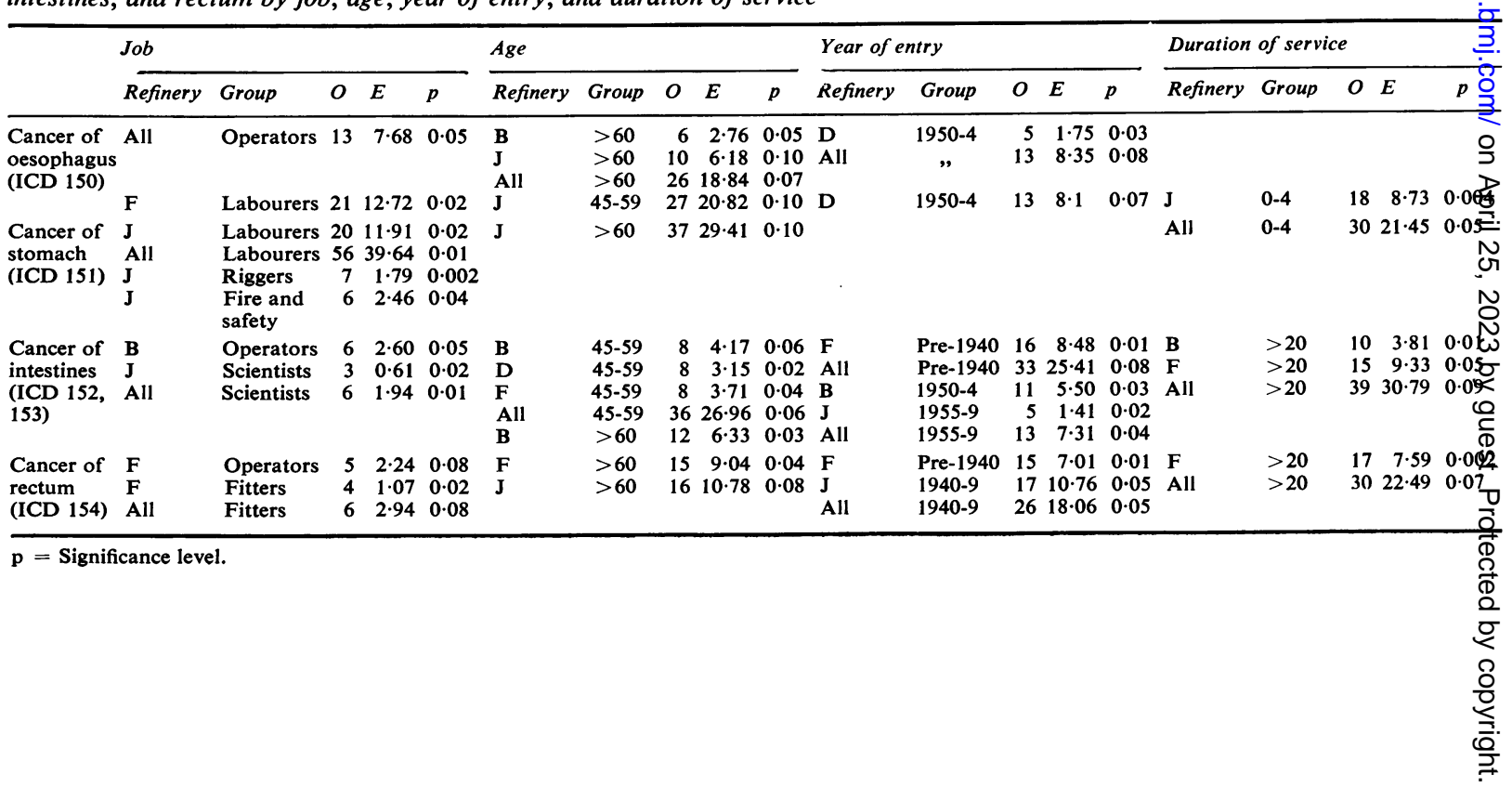


ing duration of service for both refineries $B$ and $F$ (fig 2).

Melanoma-There was a significant excess from melanoma at two refineries, although this is based

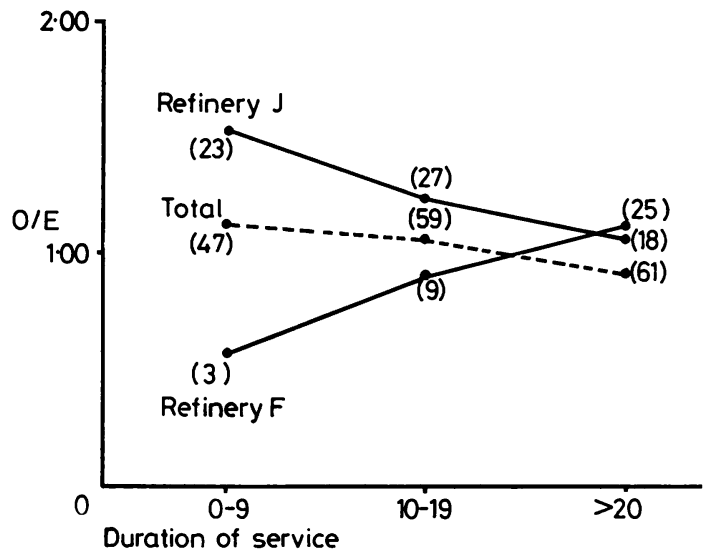

Fig 1 Ratio of observed over expected deaths $(O / E)$ by duration of service for stomach cancer for refineries $F, J$, and total study population. Number of observed deaths in parentheses.

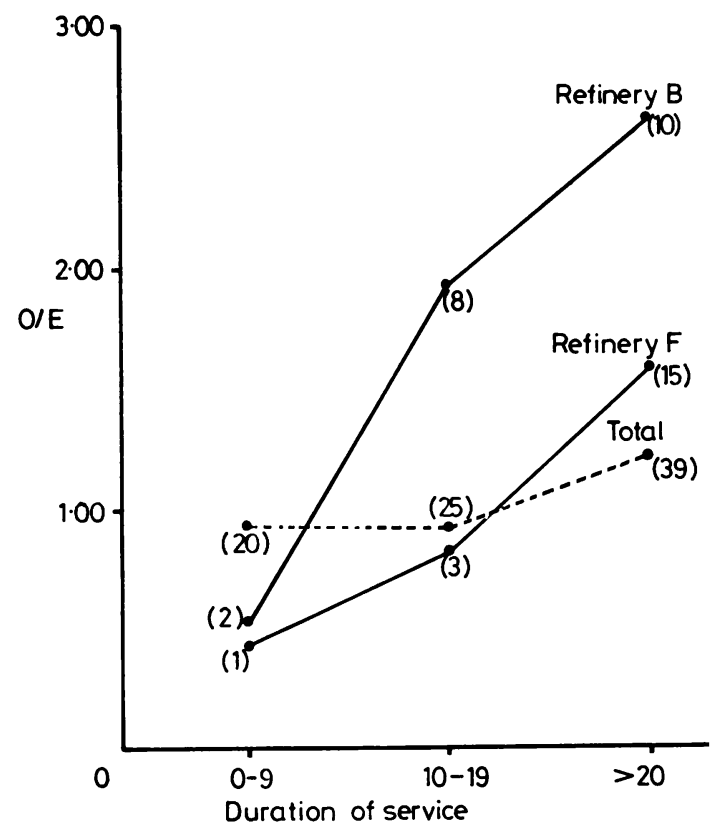

Fig 2 Ratio of observed over expected deaths $(O / E)$ by duration of service for cancer of the intestines for refineries $B, F$, and total study population. Number of observed deaths in parentheses. on small numbers (table 8). Half (7) of the deaths occurred in men aged under 45 . At one refinery four of the five who died were operators; at the other refinery the six deaths included an operator, two boilermakers, a pipefitter, a labourer, and a clerk.

Table 8 Observed and expected deaths, $O / E$, and $p$ values for melanoma, at two refineries and overall

\begin{tabular}{lclll}
\hline Refinery & $\begin{array}{l}\text { Observed } \\
\text { deaths }\end{array}$ & $\begin{array}{l}\text { Expected } \\
\text { deaths }\end{array}$ & O/E & $p$ \\
\hline B & 5 & 1.00 & 5.00 & 0.0037 \\
H & 6 & 0.89 & 6.74 & 0.0003 \\
Total study population & 14 & 6.48 & 2.16 & 0.0069 \\
\hline
\end{tabular}

Leukaemia-Overall there was a slight deficit of observed deaths compared with expected $(\mathrm{O}=30$, $E=31.96, p=0.41$ ) but a slight excess was found for fitters. In addition there were six deaths for non-malignant disease where leukaemia was mentioned as a contributory cause, two in fitters.

Lymphosarcoma-At one refinery $(\mathrm{H})$ an excess of deaths from lymphosarcoma was found, although the numbers affected were small $(O=4, E=1 \cdot 23$, $p<0.05$ ). An excess of deaths for all diseases of the lymphatic and haematopoietic tissue was found in operators at this refinery $(\mathrm{O}=7, \mathrm{E}=2.97$, $\mathrm{p}<0.05)$.

Other malignant causes-Mortality from several other malignant diseases was increased although fewer refineries and subgroups defined by job or period of entry to the refinery were concerned. An increased mortality from cancer of the liver and gall bladder was found in three of the refineries with raised mortality from gastrointestinal cancer. At refinery $\mathbf{J}$, mortality from cancers of the larynx, prostate, and kidneys and suprarenals was also increased.

\section{Discussion}

The raised patterns of mortality were not consistent in all the eight refineries studied and may perhaps be explained by differences in the work force or type of plant which are of varying size and complexity. Mortality from malignant disease was not raised at all at refineries A, C, and G. Refinery G, which is solely a petroleum bitumen manufacturing refinery, had very few men in the study, with only 57 deaths in all. Refinery A also had a small number of deaths and has been on stream only since the early 1950s. Refinery C, however, is an old one with fairly large numbers in the study. It had a very stable workforce with a gradual increase in the numbers in employment, and, unlike the other refineries, no major reduction in the workforce in the early 1960 s. Although some of 
the study population from this refinery were known to have been shale oil workers in the 1920 s, mortality was not increased in these men.

Refineries $\mathrm{A}$ and $\mathrm{H}$ are adjacent to each other. Checks for duplicate records in the study showed that men had moved frequently between these two refineries, which may have obscured the patterns of mortality. Similar results were obtained, however, when the data for these two refineries were combined for analysis.

Of the four refineries which showed an increased mortality from gastrointestinal cancer, two had some chemical plants, either integrated with the oil plants or on an adjacent site. It was not possible to exclude completely from the study all those men who worked on the chemical plants.

The refinery in which several excesses from nonmalignant causes were found in labourers had been on stream since the 1920 s. This refinery had a larger proportion than the other seven refineries of men in the study who joined the refinery before 1940 and were thus older at the study start date of 1 January 1950. This refinery also had a larger proportion of deaths in the 1950 s compared with the other refineries.

Before commenting on the results it is appropriate to indicate some of the limitations of this type of study and the problems inherent in interpreting the results, and outline some of the possible causes of variation in mortality.

The study investigated mortality only; no attempt was made to examine morbidity data such as sickness absence. Mortality studies depend greatly on the validity of the death details used, and consideration must be given to the problems of possible omission of information, the accuracy of diagnosis, and the classification and coding of the causes of death. ${ }^{24} 25$ No evidence suggested that the rate of possible inaccuracies differed between the study and the comparison populations. Although many deaths occurred in fairly small areas surrounding the refineries, there was no suggestion of any variation in the certification practices of the local doctors or coroners.

This study is essentially an a posteriori studythat is the data are used to generate hypotheses which should then be further investigated in other studies on new data. The study can be used in a limited way as an a priori study to test hypotheses generated by and investigated in other comparable studies. In any study where the number of comparisons made of observed with expected deaths is large, identification of "real" associations and, in particular, those of "industrial" origin is difficult. The detailed examination of the data carried out here has been used to describe the patterns of mortality and to search for consistency across the variations and subgroups examined. Some genuine associations may also be missed because of lack of numbers in a study or too short a period of followup. ${ }^{26}$

Factors to be taken into account when considering variations in mortality include the appropriateness of the rates used in calculating expected deaths, varying patterns of diagnosis and certification in different regions, sampling variation in the observed deaths, external (non-occupational) factors, and occupational environmental factors.

Overall the mortality of the study population is lower than that of the standard population with which it is compared. This result may be due to the comparison of an industrially employed cohort with a standard population that includes those in institutions and in unstable employment, and those already ill at the time job seeking starts or out of work due to ill health. In the absence of a specific occupational hazard this favourable mortality tends to extend to many separate causes of death. ${ }^{14}$ In this present study the observed mortality from many of the numerically large causes of death was much lower than expected on the basis of experience in the national comparison population.

Of the non-malignant diseases, only the excess from accidental fire and explosion can definitely be attributed to an occupational hazard. All but one of the deaths in this category were due to accidents at work. There is no evidence that any of the other excesses from non-malignant causes are occupational in origin.

The expected deaths were not adjusted to take account of social-class variations in mortality. Nevertheless, many of the disease groups where excesses were found in labourers have higher SMRs in social class $V$ than social class $I$, with intermediate values for classes II-IV. ${ }^{22}$ Table 5 shows the SMRs for social class $V$ for some of the disease groups in which excesses were found for labourers. If some adjustment of the expected number of deaths had been made using these figures, the observed mortality for some of the disease groups would not be greater than expected.

Lowered mortality from lung cancer accounted for almost all the deficit in "all neoplasms." An absence of heavy smokers, perhaps due to the restrictions of smoking demanded by the nature of the work, might account for this result. As yet there are no reliable data with which to investigate this, although a survey to examine the smoking habits of refinery workers is now under way. The slightly raised mortality due to lung cancer of labourers in the study is not greater than expected compared with all men of that social class. 
Increasing interest has been shown over the past few years in the relationship between benzene exposure and the risk of leukaemia. There was a deficit of observed deaths from leukaemia overall and a deficit of observed deaths from myeloid leukaemia, which has been particularly associated with exposure to benzene; no personal or environmental measures of benzene exposure were available for workers in this study, however.

An increased mortality from cancer of the gastrointestinal tract was evident in four refineries, although different year-of-entry cohorts and job groups were affected, and no location was consistently high for all subsites within the gastrointestinal tract. Most of the men affected joined the refineries before 1950 and had correspondingly long service. In general the mortality increased with increasing duration of service and latent period. Some, but not all, of the excess from stomach cancer in labourers would, however, be removed by an adjustment for social class.

Four previous studies of the oil industry have also found an increased mortality from cancers of the digestive system. ${ }^{15-18}$ Although these studies use rather different study populations, and the methods of analysis and selection of a comparison group differ, the consistency of their results, together with those of the present study, suggest that some occupational factor may be responsible for the increased mortality from cancer of the gastrointestinal tract, although the physical or chemical nature of the risk is not identifiable from any of the studies.

All the deaths from skin cancer were due to melanomas. There were no deaths from epitheliomas or scrotal cancer, which have been shown to be associated with contact with mineral oil. The incidence of melanoma has risen rapidly in England and Wales, ${ }^{27}$ although the use of age and calendar period comparison mortality rates should take account of this. Several factors that have been suggested as related to the risk of melanoma include exposure to sunshine or sunspot activity, 2829 exposure to arsenic, ${ }^{30}$ consumption of alcohol, ${ }^{31}$ and working in certain dusty occupations. ${ }^{32}$

\section{Conclusions}

This study was limited in respect of both the details collected on the study population and the duration of follow-up, but it has provided a basis for further studies. Various methods of follow-up that could be considered when assessing the results of this study include carrying out case-control studies using internally matched controls and examining information about job history and other environmental factors for the decedents and controls, extending the duration of follow-up of the study to establish whether the trends of excess mortality from certain causes occurring in workers joining the refineries before 1950 are continuing, although a minimum of ten years would be needed, and investigating whether the collection of environmental measures and detailed job assessment could provide more precise indicators of these factors to compare with the incidence of various diseases.

The data for this study were handled by Mrs Carol Fair and Ms Deborah Cummings. We benefited by help from many colleagues, especially Mrs Christine Beavan, Dr Joan Davies, Dr David Jones, and Mrs Vera Watson. The basic information was abstracted by personnel and pension departments of the companies concerned. We are grateful to the Office of Population Censuses and Surveys, DHSS, and the Registrar General for Scotland for tracing the leavers. The study benefited from the guidance of a working party of the Institute of Petroleum chaired by Dr W B L Leese. The main funding of the project was a grant from the Institute of Petroleum. The Cancer Research Campaign support of the division of epidemiology is also gratefully acknowledged.

\section{References}

${ }^{1}$ Rushton L, Alderson MR. An epidemiological survey of eight oil refineries in the UK-final report. London: Institute of Petroleum, 1980.

${ }^{2}$ Twort CC, Twort JM. The carcinogenic potency of mineral oils. Journal of Industrial Hygiene 1931;13: 204-26.

${ }^{3}$ Medical Research Council. Carcinogenic action of mineral oils: a chemical and biological study. London: HMSO, 1968. (Special report series No 306.)

${ }^{4}$ Bell J. Paraffin epithelioma of the scrotum. Edinburgh Medical Journal 1876;22:135-7.

${ }^{5}$ Scott A. On the occupation cancer of the paraffin and oil workers of the Scottish shale industry. Br Med J 1922; ii:1108-9.

${ }^{6}$ Henry SA. Cancer of the scrotum in relation to occupation. London: Oxford University Press, 1946.

${ }^{7}$ Cruickshank CND, Squire JR. Skin cancer in the engineering industry from the use of mineral oil. Br J Ind Med 1950;7:1-11.

${ }^{8}$ Parkinson GS. Benzene in motor gasoline - an investigation into possible health hazards in and around filling stations and in normal transport operations. Ann Occup Hyg 1971; 4:155-7.

${ }^{9}$ Sherwood RJ. Evaluation of exposure to benzene vapour during the loading of petrol. Br J Ind Med 1972;29:65-9.

${ }^{10}$ Baylor $\mathrm{CH}$, Weaver NK. A health survey of petroleum asphalt workers. Arch Environ Health 1968;17:210-4.

${ }^{11}$ Gafafer WH. Disabling morbidity and mortality from cancer among male employees of an oil refining company with reference to age, site and duration. Public Health $1940 ; 55: 1517-26$. 
${ }^{12}$ Hendricks NV, Berry CM, Lione JG, Thorpe JJ. Cancer of the scrotum in wax pressmen. Arch Environ Health 1959; 19:524-9.

${ }^{13}$ Wade L. Observations on skin cancer among refinery workers Arch Environ Health 1963;6:730-5.

14 Tabershaw IR. A mortality study of petroleum refinery workers. Washington DC: 1974. (API Project OH-1 No 129.)

15 Theriault G, Goulet L. A mortality study of oil refinery workers. J Occup Med 1979;21:367-70.

16 Hanis NM, Stavraky KM, Fowler JL. Cancer mortality in oil refinery workers. J Occup Med 1979;21:167-74.

17 Thomas TL, Decoufle P, Moure-Eraso R. Mortality among workers employed in petroleum refining and petrochemical plants. J Occup Med 1980;22:97-103.

${ }^{18}$ Blot WJ, Brinton LA, Fraumeni JF, Stone BJ. Cancer mortality in US counties with petroleum industries. Science 1977;198:51-3.

${ }^{19}$ World Health Organisation. Manual of the international classification of diseases, injuries and causes of death. Vols 1, 2. Geneva: WHO, 1948, 1957, 1967.

${ }^{20}$ Hill ID. Computing man years at risk. Br J Prev Soc Med 1973;26:132-4

21 Case RAM, Coghill C, Davies JM, et al. Serial mortality tables, neoplastic diseases, volume 1, England and Wales 1911-70. London: Institute of Cancer Research, 1976.

22 Office of Population Censuses and Surveys. Occupational mortality 1970-2. London: HMSO, 1978. (Series DS No 1.)

${ }^{23}$ Fox AJ, Adelstein AM. Occupational mortality: work or way of life? Journal of Epidemiology and Community Health 1978;32:73-8.

${ }^{24}$ Alderson MR. The accuracy of the certification of death and the classification of the underlying cause of death from the death certificate. London: London University, 1965. (MD thesis.)

${ }^{25}$ Waldron HA, Vickerstaff L. Intimations of quality: antemortem and post-mortem diagnosis, London: Nuffield Provincial Hospital Trust, 1977.

26 Doll R, Peto R. Mortality among doctors in different occupations. Br Med J 1977; i:1433-6.

27 Swerdlow AJ. Incidence of malignant melanoma of the skin in England and Wales and its relationship to sunshine. Br Med J 1979;ii:1324-7.

${ }^{28}$ Houghton A, Munster EW, Viola MV. Increased incidence of malignant melanoma after peaks of sunspot activity. Lancet 1978; : $759-60$.

${ }^{29}$ Crombie IK. Variation of melanoma incidence with latitude in North America and Europe. Br J Cancer 1979;40:774-81.

${ }^{30}$ Clough P. Incidence of malignant melanoma of the skin in England and Wales. Br Med J 1980;280:112.

${ }^{31}$ Williams RR. Breast and thyroid cancer and malignant melanoma promoted by alcohol induced pituitary secretion of prolactin TSH and MSH. Lancet 1976; ; : 996-9.

${ }^{32}$ Bross IDJ, Viadana E, Houten L. Occupational cancer in men exposed to dust and other environmental hazards. Arch Environ Health 1978;33:300-7. 